УДК: 629.7

\author{
Юрій Іванович Адамов ${ }^{1}$ \\ Володимир Володимирович Завальнюк (кандидат фізико-математичних наук, доцент) ${ }^{1}$ \\ Валентин Олександрович Дідик ${ }^{1}$ \\ олександр Миколайович Печорін ${ }^{2}$
}

${ }^{1}$ Військова академія (м. Одеса), Украӥна

${ }^{2}$ Національний університет оборони Украӥни імені Івана Черняховського, Київ, Украӥна

\title{
МЕТОДИКА ВИЗНАЧЕННЯ КІЛЬКОСТІ СИЛ І ЗАСОБІВ ДЕСАНТНО-ШТУРМОВИХ ВІЙСЬК ПРИ ВИКОНАННІ БОЙОВИХ ЗАВДАНЬ
}

\begin{abstract}
У статті розглядається порядок визначення необхідної і оптимальної кількості сил та засобів частин Десантно-итурмових військ 3С України, необхідних для успішного виконання поставлених бойових завдань. Запропонована математична модель грунтується на концепиії бойового потенціалу та застосовує квадратичне рівняння Ланчестера для очінки втрат $i$ необхідного початкового потенціалу сил, які проводять наступ як в ході кожного з етапів виконання багатоетапного бойового завдання, так $і$ всього завдання в иілому. На основі аналізу даних отриманих в результаті розрахунків математичної моделі, пропонується методика визначення оптимальної послідовності захоплення (знищення) об'єктів противника, при якій відсоток втрат є мінімальним (при фіксованому значенні початкового бойового потенціалу) або необхідний початковий потенціал (за заданого відсотку втрат) $\epsilon$ найменшим. Також зважено порядок дій підрозділів при можливих змінах маршрутів пересування при зміні порядку знищення сил та засобів противника, та як визначення оптимального порядку може дещо ускладнитися та потребує перебору всіх можливих варіантів. Згідно методики, наведено приклад проведення розрахунків, щзодо здійснення десантно-рейдових дій, в ході яких необхідно провести десантування на територію противника, знищити (захопити) три ичільові об'єкти та зайняти оборону в очікуванні підходу основних сил. При иьому в розрахунки враховано втрати бойового потенціалу повітряного десанту, які можуть виникнути у ході виконання бойового завдання. Результати розрахунків наведені в таблииях які містять дані, для аналізу та вибору найбільш оптимального варіанту застосування десантно-рейдових підрозділів при виконанні бойових завдань.
\end{abstract}

Ключові слова: сили та засоби, бойовий потенціал, рейдові дї̈, коефіцієнт вогневого ураження, повітряного десанту.

\section{Вступ}

Постановка проблеми. Застосування Десантно-штурмових військ (далі - ДШВ) 3С України визначено охопленням противника 3 повітря, швидкого використання результатів вогневого ураження i виконання завдань, які неможливо ефективно вирішити іншими силами та засобами в тилу противника та в ході проведення стабілізаційної операції.

Успішне виконання бойових завдань частинами ДШВ 3С України залежить від планування проведення операції (бойових дій). Проведення планування бойових дій потребує ретельного визначення оптимальної кількості сил та засобів для виконання бойових завдань, у зв'язку 3 оптимальним поповненням сил та засобів ході бойових дій. Однім із складових планування $є$ забезпечення максимально ефективного використання бойових спроможності усіх наявних у розпорядженні командира сил і засобів у ході виконання бойових завдань частини для досягнення кінцевої мети бойових дій.

Метою статті $\epsilon$ визначення необхідної i оптимальної кількість сил та засобів для частин ДШВ ЗС України є важливим етапом планування бойових дій при якому проводиться математичне моделювання ходу проведення бойових дій щодо виконання поставленої задачі. Тому стає питання щодо розроблення методики (розрахункових задач) визначення сил і засобів ДШВ ЗС України, необхідних для виконання завдань в операції (бойових діях).

\section{Виклад основного матеріалу дослідження}

Для розроблення методики визначення сил i засобів ДШВ ЗСУ, необхідних для виконання завдань в операції (бойових діях) необхідно спершу створити математичну модель визначення та оцінювання сил та засобів частин і підрозділів.

Поняття «бойового потенціалу», вперше введене у докторської дисертації Е.Г. Ананьева (ВВИА имени проф. Н.Е. Жуковского, 1958) [1], є 
основною чисельною характеристикою боєздатності підрозділів і застосовується для оцінки та порівняння сил протидіючих сторін.

Питання визначення бойового потенціалу добре розкрите у достатній кількості наукових робіт, з яких варто виділити роботи $[1-6]$.

Бойовий потенціал (далі позначається літерою М) - узагальнена характеристика бойових можливостей (вогневих, ударних і маневрених) військового формування (об'єднання, з'єднання, частини або підрозділу) або зразка військової техніки й озброєння в певному виді бойових дій (наступі, обороні тощо), який розраховується математично та позначається числом [1].

Бойовий потенціал конкретного виду озброєння визначається в ході моделювання бойових дій або аналізу набутого бойового досвіду та виражається в умовних одиницях (зазвичай, за одиницю приймають один 3 основних видів озброєнь).

Бойовий потенціал підрозділу визначається як сума бойових потенціалів відповідних видів озброєння, якими він оснащений, із урахуванням різноманітних коефіцієнтів (які можуть враховувати, наприклад, ступінь укомплектованості, підготовки особового складу, морально-психологічний стан тощо).

Перейдемо до розгляду основних способів дій Десантно-штурмових військ із використанням математичного моделювання їх зіткнень 3 противником і отриманню рівнянь для визначення кількості сил та засобів частин і підрозділів ДШВ, необхідної і достатньої для успішного виконання завдання.

Основним видом бойових дій військових частин (підрозділів) ДШВ під час їх дій у тилу противника є наступ.

Для моделювання втрат у бою далі буде застосоване квадратичне рівняння Ланчестера [7] (відзначимо, що застосування саме даної моделі не $€$ принципово необхідним і вибір іншої моделі оцінки втрат не призводить до якісних змін у наведених нижче міркуваннях):

$$
\left(M_{A, 0}^{2}-M_{A, t}^{2}\right) \lambda_{A}=\left(M_{B, 0}^{2}-M_{B, t}^{2}\right) \lambda_{B}=\text { const },
$$

де $M_{A, 0}$ та $M_{B, 0}$ - початкові потенціали сил та засобів сторін А і В, $M_{A, t}$ та $M_{B, t}$ - їх потенціали у довільний момент бою.

Початковий потенціал сил та засобів сторони A, необхідний для знищення сторони В при одночасному збереженні потенціалу величиною $M_{A, K}$, отримуємо з (1):

$$
M_{A, 0}=\sqrt{M_{A, K}^{2}+M_{B, 0}^{2} \frac{\lambda_{B}}{\lambda_{A}}\left(1-\mu_{B}^{2}\right)}
$$

при цьому її втрати в ході бою дорівнюють

$$
\Delta M_{A}=M_{A, 0}-M_{\partial, K}=M_{A, 0}\left(1-\sqrt{1-\frac{1-\mu_{3}^{2}}{\chi_{3}^{2}}}\right),
$$

де $\lambda_{B} / \lambda_{A}-$ відношення потоків потенційно успішного вогневого ураження сторони В до сторони А;

ISSN2311-7249(Print)/ISSN2410-7336(Onfine) Сучасні інббормахійні технологї̈ у сббері безпеки та оборони № 1 (40)/2021
$\mu_{B}=M_{B, K} / M_{B, 0}-$ критичний стан сил і засобів противника, при якому він стає неспроможним продовжувати бій;

коефіцієнт $\chi=\frac{M_{A}}{M_{B}} \sqrt{\frac{\lambda_{A}}{\lambda_{B}}}-$ співвідношення сил сторін (якщо $\chi>1-$ перемагає сторона $A$, при $\chi<1$ перемагає сторона $B)$.

Розглянемо задачу визначення сил та засобів повітряного десанту, необхідних для успішного послідовного виконання декількох завдань, пов'язаних 3 наступальними діями.

Нехай в ході виконання поставленої задачі необхідно захопити (знищити) три об'єкти противника з бойовими потенціалами $M_{1}, M_{2}, M_{3}$, втративши не більше заданого відсотка від початкових сил.

Вирішення цієї задачі відбувається у зворотній послідовності: спочатку, знаючи заданий відсоток втрат $z=1-M_{\partial, K} / M_{\partial, 0}$ (де $M_{\partial, 0}-$ початковий потенціал сил та засобів наших підрозділів, $M_{\partial, K}-$ потенціал сил та засобів наших підрозділів після завершення виконання всіх завдань) визначаємо потенціал сил та засобів $M_{\partial, 3}$, необхідний для знищення останнього (третього) об'єкту противника; далі на базі отриманого значення $M_{\partial, 3}$ визначаємо сили та засоби $M_{\partial, 2}, \quad$ необхідні для знищення передостаннього об'єкту тощо.

Потенціал сил та засобів $M_{\partial, 3}$ наступаючої сторони, необхідних для захоплення (знищення) третього об'єкту противника $\left(M_{3}\right)$ зі збереженням відповідного значення потенціалу $M_{\partial, K}$ сил наступаючою сторони, визначається рівнянням (2):

$$
M_{\partial, 3}=\sqrt{M_{\partial, K}^{2}+M_{3}^{2} \frac{\lambda_{\partial}}{\lambda_{3}}\left(1-\mu_{3}^{2}\right)}
$$

де $\lambda_{\partial} / \lambda_{3}-$ відношення потоків вогневого ураження наступаючої сторони до сторони, що обороняється;

$\mu_{3}$ - критичний стан сил і засобів противника, при якому він стає неспроможнім продовжувати бій (береться на основі розвідданих).

Аналогічним чином, сили та засоби наступаючої сторони перед захопленням (знищенням) другого об'єкту повинні бути рівними

$$
M_{\partial, 2}=\sqrt{M_{\partial, 3}^{2} \frac{1}{l_{23}^{2}}+M_{2}^{2} \frac{\lambda_{2}}{\lambda_{\partial}}\left(1-\mu_{2}^{2}\right)},
$$

де $\lambda_{2}$ - коефіцієнт вогневого ураження сил та засобів другого противника;

$\mu_{2}$ - критичний стан сил і засобів противника, при якому він не спроможний продовжувати бій;

$l_{23}$ - коефіцієнт, що вказує можливі втрати бойового потенціалу повітряного десанту від дій ДРГ, удару авіації, артилерії та ураження при подоланні міного загородження у проміжку між захопленням (знищенням) другого та третього об'єкту $\left(0<l_{23} \leq 1\right.$, якщо втрати відсутні: $\left.l_{23}=1\right)$.

Остаточний вираз для початкової кількості сил та засобів $\mathrm{M}_{\text {д,0}}$, мінімально необхідної для успішного виконання всієї послідовності задач 
дорівнює:

$$
\begin{aligned}
M_{\partial, 0} & =\left(M_{1}^{2} \frac{\lambda_{1}}{\lambda_{\partial}} \frac{\left(1-\mu_{1}^{2}\right)}{l_{01}^{2}}+M_{2}^{2} \frac{\lambda_{2}}{\lambda_{\partial}} \frac{\left(1-\mu_{2}^{2}\right)}{l_{01}^{2} l_{12}^{2}}+\right. \\
& \left.+M_{3}^{2} \frac{\lambda_{3}}{\lambda_{\partial}} \frac{\left(1-\mu_{3}^{2}\right)}{l_{01}^{2} l_{12}^{2} l_{23}^{2}}+M_{\partial, K}^{2} \frac{1}{l_{01}^{2} l_{12}^{2} l_{23}^{2}}\right)^{1 / 2},
\end{aligned}
$$

де $l_{12}$ задає можливі втрати повітряного десанту у проміжку між захоплення (знищенням) першого та другого об'єкту;

$l_{01}$ - коефіцієнт, що вказує можливі втрати бойового потенціалу повітряного десанту у проміжку між початком проведення рейдових дій та захоплення (знищенням) першого об'єкту.

Повертаючись до значення відсотку максимально допустимих витрат $z=1-\frac{M_{\partial, K}}{M_{\partial, 0}}>0$ повітряного десанту в ході виконання завдання та перетворюючи рівняння (3) відповідним чином отримуємо вираз для визначення величини $\mathrm{M}_{\text {д,0 }}$ через задане значення відсотку витрат:

$$
M_{\partial, 0}=\frac{\sqrt{M_{1}^{2} \frac{\lambda_{1}}{\lambda_{\partial}} \frac{\left(1-\mu_{1}^{2}\right)}{l_{01}^{2}}+M_{2}^{2} \frac{\lambda_{2}}{\lambda_{\partial}} \frac{\left(1-\mu_{2}^{2}\right)}{l_{0 l}^{2} l_{12}^{2}}+M_{3}^{2} \frac{\lambda_{3}}{\lambda_{\partial}} \frac{\left(1-\mu_{3}^{2}\right)}{l_{0 l}^{2} l_{12}^{2} l_{23}^{2}}}}{\sqrt{1-\frac{(1-z)^{2}}{l_{0}^{2} l_{12}^{2} l_{23}^{2}}}},
$$

де $M_{\partial, 0}$ - склад сил і засобів перед початком проведення рейдових дій;

$M_{\partial, 1}, M_{\partial, 2}, M_{\partial, 3}$ - склад сил і засобів перед початком захоплення (знищенням) першого, другого і третього об'єктів відповідно;

$M_{\partial, K}$ - склад сил і засобів після завершення виконання завдань;

\section{$z$ - відсоток втрат.}

У випадку довільного числа $N$ бойових дій попередня рівність (4) набуває вигляду:

$$
M_{\partial, 0}=\frac{\sqrt{\sum_{j=1}^{N} M_{j}^{2} \frac{\lambda_{i}}{\lambda_{\partial}} \frac{\left(1-\mu_{i}^{2}\right)}{\prod_{i=1}^{j} l_{i-1, i}^{2}}}}{\sqrt{1-\frac{(1-z)^{2}}{\prod_{i=1}^{N} l_{i-1, i}^{2}}}} .
$$

Отримане рівняння не лише дозволяє визначити початковий потенціал сил та засобів наступаючої сторони, необхідний для виконання всієї послідовності боїв, але й проаналізувати його залежність від різних факторів (рис. 1 і 2) та визначити оптимальну послідовність захоплення (знищення) об'єктів противника, при якій відсоток втрат буде мінімальним або необхідний мінімальний початковий потенціал за заданого відсотку втрат (табл. 1 і 2).

Основним фактором, що впливає на вибір порядку захоплення (знищення) об’єктів противника $\epsilon$ добуток квадрата їх бойового потенціалу та коефіцієнту успішності вогневого ураження противника $M_{j}^{2} \lambda_{j}$. Як правило, найбільш доцільно атакувати об'єкти противника у порядку зменшення цього добутку. Однак, приймаючи до уваги можливі зміни маршрутів пересування при зміні порядку знищення сил та засобів противника (i, відповідно, коефіцієнтів $l_{\alpha \beta}$ ), визначення оптимального порядку може дещо ускладнитися та потребує перебору всіх можливих варіантів. Для спрощення процедури перебору доцільно побудувати таблицю з усіма можливими порядками захоплення (знищення) об'єктів противника, визначити всі відповідні коефіцієнти й обчислити результуючий відсоток втрат (або значення $\mathrm{M}_{\text {д,0 }}$ за умови фіксованого відсотку втрат), після чого обрати оптимальний варіант.

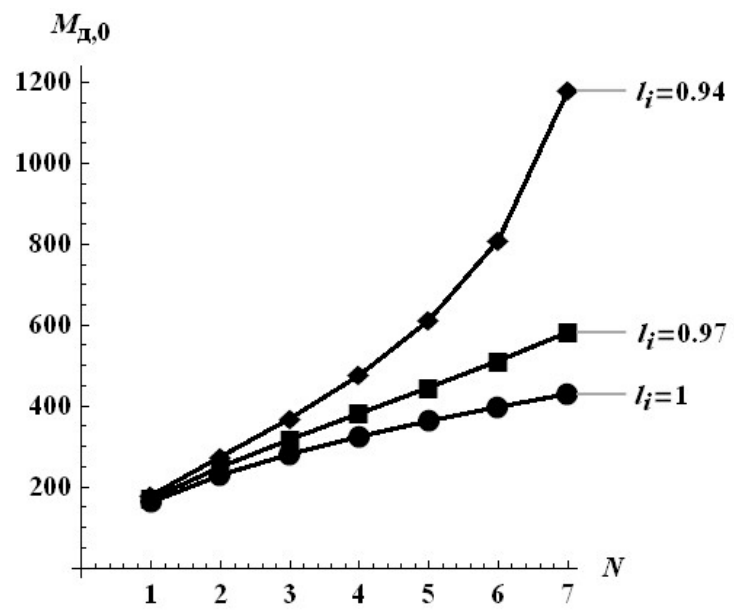

Рис. 1. Залежність необхідного початкового

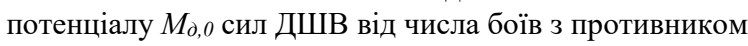
протягом рейду та значення коефіцієнту втрат $l_{i}$ при пересуванні між захоплення (знищенням) об'єктів (всі $l_{i}$ приймаються рівними).

Противники вважаються однаковими, при $z=0.4(40 \%), \mathrm{M}_{i}=100, \lambda_{i} / \lambda_{\text {д }}=3, \mu_{i}=0.25(25 \%)$

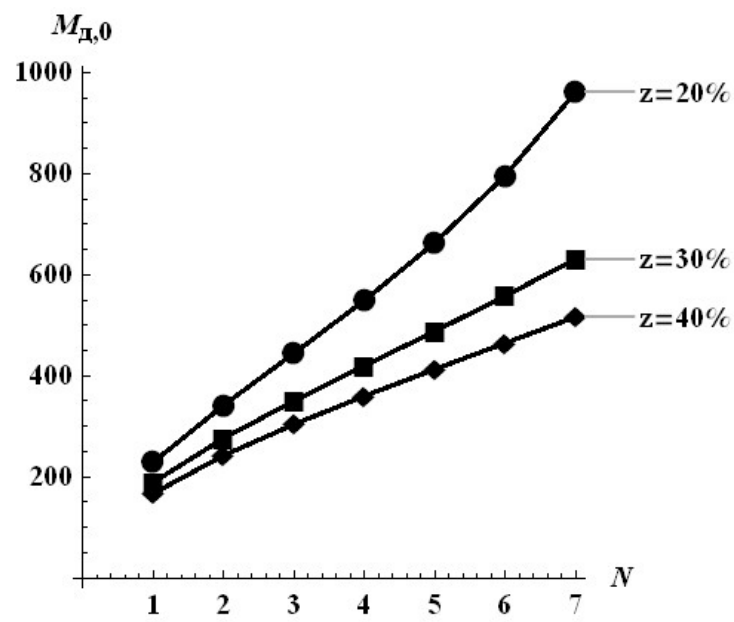

Рис. 2. Залежність необхідного початкового потенціалу $M_{\partial, 0}$ сил ДШВ від числа боїв 3 противником протягом рейду та значення цільового відсотку втрат Z сил ДШВ.

Противники вважаються однаковими, при $l_{i}=0.98, \mathrm{M}_{i}=100, \lambda_{i} / \lambda_{\text {д }}=3, \mu_{i}=0.25(25 \%)$

Розглянемо приклад застосування отриманого рівняння на прикладі проведення десантнорейдових дій, в ході яких необхідно провести десантування на територію противника, знищити 
(захопити) три цільові об'єкти та зайняти оборону в очікуванні підходу основних сил.

Загальний бойовий потенціал $M_{j}$ сил та засобів противника а також очікуване співвідношення $\lambda_{j} / \lambda_{\partial}$ коефіцієнтів успішності вогневого ураження противника $\lambda_{j}$ та втрати повітряного десанту від вогневого ураження противником $\lambda_{\partial}$, складають:

$$
\begin{array}{ll}
M_{1}=75 ; & \lambda_{1} / \lambda_{\partial}=2 ; \\
M_{2}=70 ; & \lambda_{2} / \lambda_{\partial}=3 ; \\
M_{3}=60 ; & \lambda_{3} / \lambda_{d}=2 .
\end{array}
$$

Критичний стан сил і засобів всіх трьох об'єктів противника $\left(\mu_{1}, \mu_{2}, \mu_{3}\right)$, при якому вони втрачають спроможність продовжувати утримувати визначені позиції, оцінюється у 40\% $\left(\mu_{1}=\mu_{2}=\mu_{3}=0.4\right)$.

Можливі втрати бойового потенціалу повітряного десанту від дій артилерії та авіації противника, а також при подоланні мінних полів та інших можливих загороджень при пересуванні між районом збору та об’єкта противника можуть становити:

між районом збору та розташування першого об'єкта противника якій підлягає захопленню (знищенню): $5 \%\left(l_{01}=0.95\right)$;

між розташуванням першого об'єкта противника та другого об'єкта противника якій підлягає захопленню (знищенню): $10 \%\left(l_{12}=0.90\right)$;

між розташуванням другого об'єкта противника та третього об'єкта противника якій підлягає захопленню (знищенню): $15 \%\left(l_{23}=0.85\right)$.

Потенціал сил та засобів повітряного десанту, мінімально необхідний для успішного ведення оборони, оцінюється у $M_{\partial, K}=80$ умовних одиниць [8].

Застосовуючи рівняння (3) для обчислення мінімально необхідного початкового потенціалу сил та засобів повітряного десанту для успішного виконання завдання в ході рейдових дій, отримуємо:

$$
\begin{aligned}
& M_{\partial, 0}=\left(\frac{75^{2} \cdot 2\left(1-0.4^{2}\right)}{0.98^{2}}+\frac{70^{2} \cdot 3\left(1-0.4^{2}\right)}{0.98^{2} \cdot 0.9^{2}}+\right. \\
& \left.+\frac{60^{2} \cdot 2\left(1-0.4^{2}\right)}{0.98^{2} \cdot 0.9^{2} \cdot 0.85^{2}}+\frac{80^{2}}{0.98^{2} \cdot 0.9^{2} \cdot 0.85^{2}}\right)^{1 / 2}=219 .
\end{aligned}
$$

Тобто початковий потенціал сил та засобів повітряного десанту $M_{\partial, 0}$ повинен становити не менше ніж 219 умовних одиниць.

За умови можливості вибору порядку знищення (захоплення) відомих об'єктів противника у ході рейдових дій та незмінності всіх інших факторів умов даного прикладу оптимальним порядком знищення противника (тим, що вимагає найменшого початкового потенціалу сил та засобів повітряного десанту або призводить до найменших втрат) $€$ наступний: $M_{2}, M_{1}, M_{3}$. Найгіршим варіантом $є$ : $M_{3}, M_{1}, M_{2}$ (див. таблицю 1).

Аналогічним чином можна провести аналіз за умови заданого початкового потенціалу сил i засобів підрозділу повітряного десанту (таб. 2).
Таблиця 1

Порівняння значень $M_{\partial, 0}$ за умови $M_{\partial, K}=80$ залежно від порядку проведення боїв

\begin{tabular}{|c|c|}
\hline $\begin{array}{c}\text { Порядок } \\
\text { захоплення (знищення) } \\
\text { об'єктів противника }\end{array}$ & $\begin{array}{c}\text { Мінімально необхідний } \\
\text { початковий потенціал сил та } \\
\text { засобів повітряного десанту }\end{array}$ \\
\hline$M_{1}, M_{2}, M_{3}$ & $M_{\partial, 0}=219$ \\
\hline$M_{1}, M_{3}, M_{2}$ & $M_{\partial, 0}=226$ \\
\hline$M_{2}, M_{1}, M_{3}$ & $M_{\partial, 0}=217$ \\
\hline$M_{2}, M_{3}, M_{1}$ & $M_{\partial, 0}=221$ \\
\hline$M_{3}, M_{1}, M_{2}$ & $M_{\partial, 0}=228$ \\
\hline$M_{3}, M_{2}, M_{1}$ & $M_{\partial, 0}=224$ \\
\hline
\end{tabular}

Таблиця 2

Порівняння значень $M_{\partial, \kappa}$ за умови $M_{\partial, 0}=219$ залежно від порядку проведення бойових дій та відповідного відсотку втрат потенціалу сил та засобів повітряного десанту в ході рейдових дій

\begin{tabular}{|c|c|c|}
\hline $\begin{array}{c}\text { Порядок } \\
\text { (знищенння) } \\
\text { об'єктів } \\
\text { противника }\end{array}$ & $\begin{array}{c}\text { Кінцевий } \\
\text { понціал сил та } \\
\text { повобів } \\
\text { десаняного }\end{array}$ & $\begin{array}{c}\text { Відсоток втрат } \\
\text { бойового } \\
\text { потенціалу } \\
\text { повітряного } \\
\text { десанту }\end{array}$ \\
\hline$M_{1}, M_{2}, M_{3}$ & $M_{\partial, 0}=219$ & $63 \%$ \\
\hline$M_{1}, M_{3}, M_{2}$ & $M_{\partial, 0}=226$ & $69 \%$ \\
\hline$M_{2}, M_{1}, M_{3}$ & $M_{\partial, 0}=217$ & $\underline{62 \%}$ \\
\hline$M_{2}, M_{3}, M_{1}$ & $M_{\partial, 0}=221$ & $65 \%$ \\
\hline$M_{3}, M_{1}, M_{2}$ & $M_{\partial, 0}=228$ & $70 \%$ \\
\hline$M_{3}, M_{2}, M_{1}$ & $M_{\partial, 0}=224$ & $68 \%$ \\
\hline
\end{tabular}

3 аналізу наведених у таблиці 2 результатів розрахунків бачимо, що різниця у відсотку втрат між оптимальним i найгіршим порядками знищення цілей становить $8 \%$ від початкового потенціалу сил і засобів повітряного десанту.

\section{Висновки і перспективи подальших досліджень}

Дана методика дозволяє проводити дослідження 3 оцінці ефективності застосування підрозділів ДШВ. Її реалізація разом зі спеціально розробленим програмним забезпеченням, яке буде використовуватись у майбутніх інформаційноаналітичних системах, або ж типовим програмним забезпеченням (як Microsoft Excel) дозволить значно пришвидшити обробку результатів розрахунків бойового потенціалу як підрозділу ДШВ так і противника. Це в свою чергу дозволить командуванню значно скоротити час, необхідний для прийому рішень щодо застосування підрозділів, а у випадку необхідного миттєвого прийняття рішення в ході перебування підрозділів ДШВ у бойовому зіткненні - зберегти життя особового складу, змоделювавши можливі результати бойових дій та обравши оптимальний варіант їх проведення.

Перевага запропонованої методики полягає у легкості проведення розрахунків: основна задача тих, хто буде користуватись нею, - заздалегідь і правильно визначити всі коефіцієнти, що входять в рівняння; основна складність - коефіцієнти та показники, що стосуються сил противника, визначення яких є одним із завдань розвідки. 


\section{Jimepamypa}

1. Печорін О.М. Особливість тактики застосування військових частин в умовах ведення гібридної війни. К.НУОУ / Печорін О.М. // Сучасні інформаційні технології у сфері безпеки та оборони. - 2016. - № 3(27). - С. 161-166. 2.Печорін О.М. Рекомендації щодо підвищення живучості десантно-штурмового загону під час підготовки і ведення десантно-ударних дій. К.НУОУ / Печорін О.М. // Сучасні інформаційні технології у сфері безпеки та оборони. - 2016. - № 1(25). - С. 180-185. 3. Бонин А.С. О боевых потенциалах образцов ВВТ, формирований и соотношениях сил группировок сторон. Загальні питання 241 А.С. Бонин, Г.И. Горчица. Военная мысль. - 2010. - № 4. - С. 61-67. 4. Брезгин В.С. О методологии оценки боевых потенциалов вооружения и военной техники и воинских формирований / В.С. Брезгин, А.И. Буравлев // Военная мысль. - 2010. - № 8. - С. 41-48. 5. Скорик А.Б. Анализ общей методологии формирования требований к военно-техническим системам и вооружению ЗРВ. Ч. 1. Эволюционное развитие оперативнотактических требований / А.Б. Скорик, Б.А. Демидов // Системи озброєння і військова техніка. - 2010. - № 3 (23). - С. 75-81. 6. Луценко Е.В. Автоматизированный системнокогнитивный анализ в управлении активными объектами (системная теория информации и ее применение в исследовании экономических, социально-психологических, технологических и организационно-технических систем): монография / Е.В. Луценко. - Краснодар: КубГАУ, 2002. - 605 с. 7. Alan Washburn, Moshe Kress. Combat modelling. International series in operation research \& management science. Springer: 2009. DOI: $10.1007 / 978-1-4419-0790-5$. 8. Збірник тактичних розрахунків 3 прикладами: навчальний посібник. Киів. / колектив авторів. - К.: НУОУ ім. Івана Черняховського. 2018. - С. 25-26.

\title{
МЕТОДИКА ОПРЕДЕЛЕНИЯ КОЛИЧЕСТВА СИЛ И СРЕДСТВ ДЕСАНТНО-ШТУРМОВЫХ ВОЙСК ПРИ ВЫПОЛНЕНИИ БОЕВЫХ ЗАДАЧ
}

\author{
Юрий Иванович Адамов ${ }^{1}$ \\ Владимир Владимирович Завальнюк (кандидат физико-математических наук, доцент) ${ }^{1}$ \\ Валентин Александрович Дидык ${ }^{1}$ \\ Печорин Александр Николаевич ${ }^{2}$
}

\author{
${ }^{1}$ Военная академия (2. Одесса), Украина \\ ${ }^{2}$ Национальний университет обороны Украины имени Ивана Черняховского, Киев, Украина
}

\begin{abstract}
В статье рассматривается порядок определения необходимой и оптимальной количества сил $и$ средств частей десантно-итурмовой войск ВС Украины, необходимых для успешного выполнения поставленных боевых задач. Предложенная математическая модель основывается на концепции боевого потенциала и применяет квадратическое уравнение Ланчестера для оценки потерь и необходимого начального потенциила сил, которые проводят наступление как в ходе каждого из этапов выполнения многоэтапного боевой задачи, так и всего задания в целом. На основе анализа данных полученных в результате расчетов математической модели, предлагается методика определения оптимальной последовательности захвата (уничтожения) объектов противника, при которой процент потерь является минимальньмм (при фиксированном значении начального боевого потенциала) или необходим начальный потенциил (при заданном проиенте потерь) является наименьшим. Также взвешенно порядок действий подразделений при возможных изменениях маршрутов передвижения при изменении порядка уничтожения сил и средств противника, и как определение оптимального порядка может несколько осложниться и требует перебора всех возможных вариантов. Согласно методике, приведен пример проведения расчетов, по осуществлению десантно-рейдовых действий, в ходе которых необходимо провести десантирование на территорию противника, уничтожить (захватить) три целевые объекты и занять оборону в ожидании подхода основных сил. При этом в расчет учтено потери боевого потеничила воздушного десанта, которые могут возникнуть в ходе выполнения боевой задачи. Результаты расчетов приведены в таблицах с данными, для анализа и выбора наиболее оптимального варианта применения десантно-рейдовых подразделений при выполнении боевых задач.

Ключевые слова: силы и средства, боевой потенциил, рейдовые действия, коэффициент огневого поражения, воздушного десанта.
\end{abstract}

\section{EVALUATION OF ASSAULT TROOPS COMBAT POTENTIAL NECESSARY FOR SUCCESSFUL COMPLETION OF MULTI-STAGED COMBAT MISSIONS}

\author{
Yuri Adamov ${ }^{I}$ \\ Volodymyr Zavalnyuk (Candidate of Physical and Mathematical Sciences, Associate Professor) ${ }^{1}$ \\ Valentin Didyk ${ }^{1}$ \\ Oleksandr Pechorin ${ }^{2}$
}




\section{${ }^{1}$ Odesa Military Academy, Ukraine \\ ${ }^{1}$ National Defence University of Ukraine named after Ivan Cherniakhovskyi, Kyiv, Ukraine}

The article considers the procedure for determining the necessary and optimal number of forces and means of units of the Assault Troops of the Armed Forces of Ukraine, necessary for the successful execution of combat missions. The proposed mathematical model is based on the concept of combat potential and uses the Lanchester quadratic equation to estimate the losses and the required initial potential of the forces conducting the offensive during each stage of the multi-stage combat mission and the task as a whole. Based on the analysis of the data obtained as a result of calculations of the mathematical model, a method of determining the optimal sequence of capture (destruction) of enemy objects, in which the percentage of losses is minimal (at a fixed value of initial combat potential) or the required initial potential (for a given percentage of losses) is the smallest. The order of actions of units in case of possible changes of routes of movement at change of the order of destruction of forces and means of the enemy is considered also, and as definition of an optimum order can become a little complicated and needs search of all possible options. According to the methodology, there is an example of calculations on the implementation of airborne raids, during which it is necessary to land on enemy territory, destroy (capture) three targets and take the defense in anticipation of the approach of the main forces. At the same time, the calculations take into account the losses of the combat potential of the airborne troops, which may occur during the execution of the combat mission. The results of the calculations are given in the tables containing the data for the analysis and selection of the most optimal option for the use of airborne raids in combat missions.

Key words: forces and means, combat potential, raids, coefficient of fire damage, airborne.

\section{References}

1. Pechorin O.M. (2016) Osoblyvistj taktyky zastosuvannja vijsjkovykh chastyn $\mathrm{v}$ umovakh vedennja ghibrydnoji vijny [Feature of tactics of application of military units in the conditions of conducting hybrid war]. K.NUOU / Pechorin O.M/ // Suchasni informacijni tekhnologhiji u sferi bezpeky ta oborony. - 2016. - №3(27). - S. 161-166. 2. Pechorin O.M. Rekomendaciji shhodo pidvyshhennja zhyvuchosti desantno-shturmovogho zaghonu pid chas pidghotovky i vedennja desantno-udarnykh dij. [Recommendations for increasing the survivability of the assault detachment during the preparation and conduct of airborne strikes]. K.NUOU / Pechorin O.M. // Suchasni informacijni tekhnologhiji u sferi bezpeky ta oborony. 2016. - №1(25). - S. 180-185. 3. Bonin A.C. O boevyih potentsialah obraztsov VVT, formirovaniy i sootnosheniyah sil gruppirovok storon. [On the combat potential of weapons and military equipment samples, formations and the balance of forces of the groupings of the sides.] / A.C. Bonin, G.I. Gorchitsa // Voennaya myisl. - 2010. - №4. - S.61-67. 4. Brezgin V.S. O metodologii otsenki boevyih potentsialov vooruzheniya i voennoy tehniki i voinskih formirovaniy [On the methodology for assessing the combat potentials of weapons and military equipment and military formations] / V.S. Brezgin, A.I. Buravlev // Voennaya myisl. - 2010. - № 8. - S.41-48. 5. Skorik A.B. Analiz obschey metodologii formirovaniya trebovaniy $\mathrm{k}$ voenno-tehnicheskim sistemam $\mathrm{i}$ vooruzheniyu ZRV. [Analysis of the general methodology for the formation of requirements for military-technical systems and weapons of air defense systems] Ch. 1. Evolyutsionnoe razvitie operativno-takticheskih trebovaniy / A.B. Skorik, B.A. Demidov // Sistemi ozbroEnnya I vIyskova tehnIka. - 2010. - №3 (23). - S.75-81. 6. Lutsenko E.V. Avtomatizirovannyiy sistemnokognitivnyiy analiz $\mathrm{v}$ upravlenii aktivnyimi ob'ektami (sistemnaya teoriya informatsii i ee primenenie $\mathrm{v}$ issledovanii ekonomicheskih, sotsialno-psihologicheskih, tehnologicheskih i organizatsionno-tehnicheskih sistem): monografiya [Automated system-cognitive analysis in the management of active objects (system theory of information and its application in the study of economic, sociopsychological, technological and organizational-technical systems): monograph] / E.V. Lutsenko. - Krasnodar: KubGAU, 2002. - 605 s. 7. Alan Washburn, Moshe Kress. Combat modelling. International series in operation research \& management science. Springer: 2009. DOI: 10.1007/9781-4419-0790-5. 8. ZbIrnik taktichnih rozrahunkIv z prikladami: navchalniy posIbnik. [Collection of tactical calculations with examples: a textbook] KiIv. / kolektiv avtorIv. - K.: NUOU Im. Ivana Chernyahovskogo. 2018. S.25-26. 